\title{
Replacement of several single function generator protection relay at Badak LNG
}

\author{
Iqbal Nusya Perdana* \\ Lead Electrical Engineer, Technical Department, Badak LNG, Indonesia
}

\begin{abstract}
Badak LNG is a company that operates the largest LNG Plant in Indonesia with maximum production capacity of 22.5 MTPA. The company operates twelve (12) steam turbine generators and one gas turbine generator and one diesel engine generator to supply electricity for process, utility, storage, loading and plant support facility areas, which constitutes the criticality of power generator equipment to keep the reliability of production process. Generator protection relay is one of the equipment that monitors and protects the generator from fault resulting from either internal or external disturbance, preventing the generator from serious damages. Before 2015, Badak LNG used single function relays to protect the generators. The generators are protected by stator differential protection (87), current unbalance (46), loss of excitation (40), reverse power (32), time overcurrent with voltage restraint $(51 \mathrm{~V})$, and time overcurrent ground (51G). These single function relays wield more disadvantages compared to the newer technology held by the digital relays. Since 2015, Badak LNG have started to replace the single function generator protection relays with the digital type ones.
\end{abstract}

\section{Introduction}

Badak LNG (PTB) is a natural gas liquefaction plant situated in Bontang, East Kalimantan, Indonesia. Operating since 1977, PTB has eight process trains, namely Train A to $\mathrm{H}$, with a maximum sustainable capacity of 22.1 MTPA (Million Tonnes per Annum). Badak LNG is comprised of three main areas which are: Process Trains, Storage and Loading, and Utilities. Utilities area covers several systems that supports the LNG production process, such as: electricity supply, steam supply, cooling water system supply, instrument air, nitrogen system and water treatment system.

In terms of electricity supply as can be viewed in figure 1, Badak LNG has fourteen (14) generators to supply power electricity to its system. These generators are equipped with several protections to prevent damages subject to generator and its prime mover from occurrences of failures. However, the vast majority of the generator protections in Badak LNG still utilizes electromechanical relay which only has single purposive function. Over times, these electromechanical relays suffer from problems due to reliability and obsolescence issues.

\footnotetext{
* Corresponding author: iqbalnusya@badaklng.co.id
} 
Facing this issue, Badak LNG had an intention to start replacing the existing technology (electromechanical relays) with the latest technology which possesses several advantages, some of which are more complete protection, diagnostic capabilities for optimization, and other operational advantages e.g. sequence of events, present values, and communication capabilities. Since 2015, Badak LNG have started to replace these electromechanical relays with the digital type ones. Upgrading protection technology was the best solution to increase the reliability of generators in Badak LNG plant.

\section{Generator protection}

Generator is a machine that converts mechanical energy into electrical energy. Generator works based on the principle of Faraday's law of electromagnetic induction. In Badak LNG, generator plays an important role as the backbone of utility systems in producing electricity. Consequently, generator becomes a critical equipment for the dependence of LNG production on electric power supply and therefore, it shall be protected from internal or external faults and operated properly to ensure the sustainability of electricity.

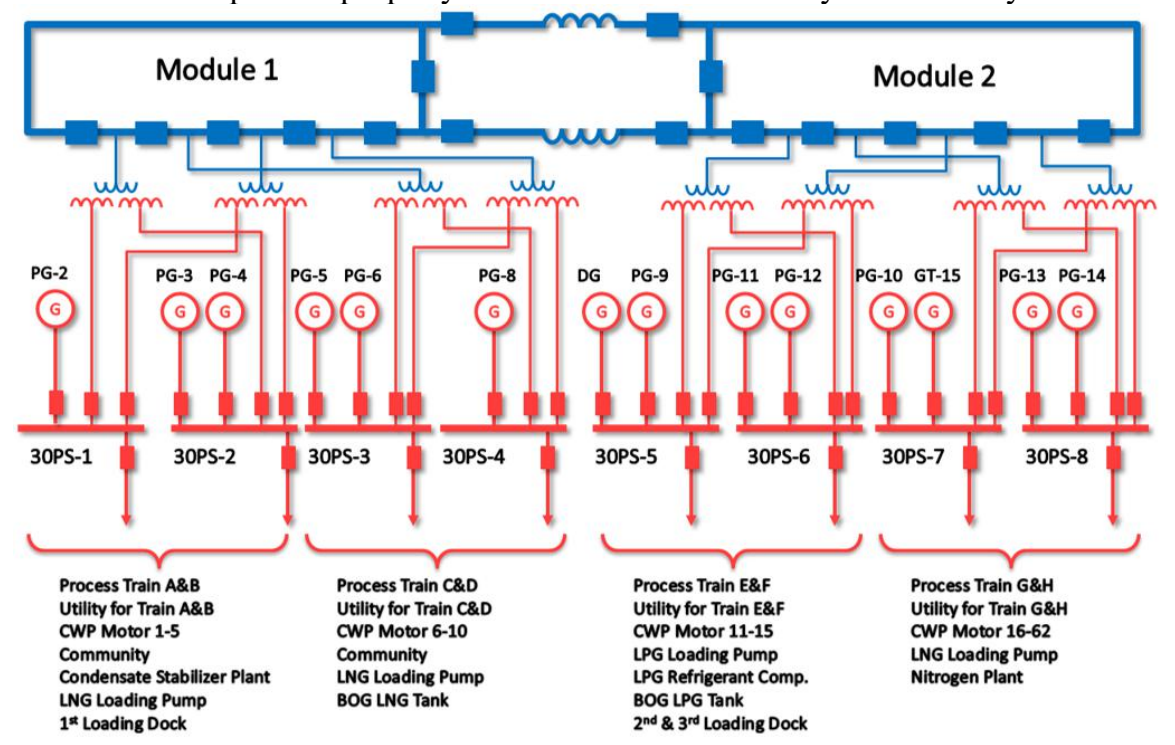

Fig. 1. Overall Single Line Diagram Badak LNG.

Generator has to be protected not only from electrical faults (stator and rotor faults) and mechanical problems, but also from adverse system interaction if it is going out of step with the rest of system, loss of field winding, etc. Under certain situations e.g. internal faults, the generator has to be isolated quickly, while other problems might only require alarms to alert the operator.

\section{Replacement relay}

Generator protection in Badak LNG utilizes single function electromechanical relays. These electromechanical relays, as can be viewed figure 2, have been suffering from several problems due to reliability and obsolescence issues, see table 1. Manufacturer has stated that their product will be obsolete starting in 2019 which translates to no further spare-part related support will be available by then. On account of this issue, Badak LNG has to start to do replacement program immediately. Newer technology, which is digital protection as 
can be viewed in figure 3, offers more advantages compared to the electromechanical relays, some of which are: more complete protection, diagnostic improvement, life extension with minimum effort, and operational advantages e.g. events recorder and log sheet.

Table 1. Status Generator Protection in Badak LNG.

\begin{tabular}{|c|l|c|c|c|}
\hline No & \multicolumn{1}{|c|}{ Protection } & ANSI & Model & Status \\
\hline 1. & Stator Differential Protection & 87 & CFD & Obsolete in 2019 \\
\hline 2. & Current Balance & 46 & SGC & Obsolete in 2019 \\
\hline 3. & Loss of Excitation & 40 & CEH & Obsolete in 2019 \\
\hline 4. & Anti Motoring & 32 & GGP & Obsolete in 2019 \\
\hline 5. & Overcurrent Voltage Restrain & $51 \mathrm{~V}$ & IFCV & Obsolete in 2019 \\
\hline 6. & Stator Ground Fault & $51 \mathrm{GN}$ & IAC & Obsolete \\
\hline
\end{tabular}

Nowadays, technology of protective relay has used microprocessor and microcontroller and well known as numerical or digital relay. These relays offer several unique advantages. These include more complete protection, diagnostic capabilities, life extension with minimal implementation and operational advantages of sequence of events, present values and communication capabilities.

With these all advantageous from digital relay, operation and maintenance are able to maintain the performance reliability of generator easily. In order to ensure new digital relay has same setting with the existing relay, current-time characteristic is needed to be examined between digital relay and existing relay.

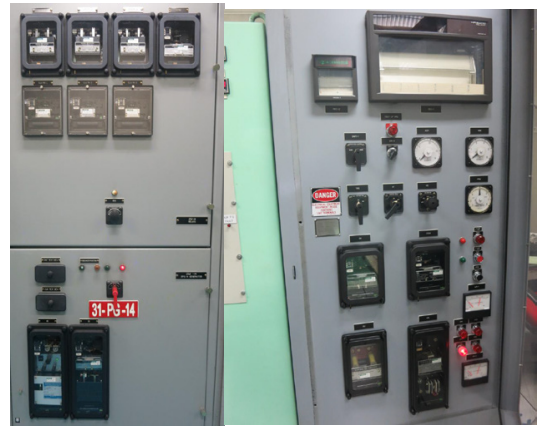

Fig. 2. Electromechanical relay for generator protection.

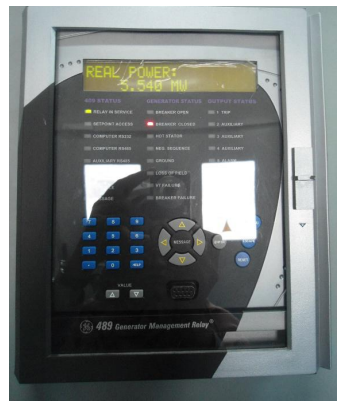

Fig. 3. New digital relay protection for generator.

\subsection{Stator differential protection (87G)}

Stator Differential Protection protects generator windings against internal faults e.g. phaseto-phase and three phase-to-ground faults. This type of fault is very serious due to the ability of high current to flow and produce significant amount of damages to the winding if it is allowed to last. This protection system requires two identical current transformers which are mounted on both sides of the protection zone. The secondary terminals of the current transformers are connected in stars, and their end terminals are connected through the pilot wire as can be viewed in figure 4 .

The existing stator differential protection is electromechanical relay with single slop setting of $100 \%$ percentage slope and minimum pick-up of $0.2 \mathrm{~A}$ on secondary side. This relay is adjusted at the factory and the setting cannot be changed. Based on IEEE Std 242 Protection and Coordination of Industrial and Commercial Power System [1], the 
percentage slope characteristic can vary from 5\% at low values of through current up to $50 \%$ or more at high values of through current. This characteristic result in a relay that is sensitive to internal faults and insensitive to CT error currents during severe external faults. Since the new digital relay could provide double slope protection, as can be viewed in figure 5 , a new setting must be considered. Referring to the study, the optimum value of percentage slope setting is $25 \%$ (slope 1) at low and $95 \%$ (slope 2) at high. The minimum pick-up current setting of new relay having range of $0.05 \mathrm{CT}$ secondary or $0.25 \mathrm{~A}$ (Using CT 1000:5).

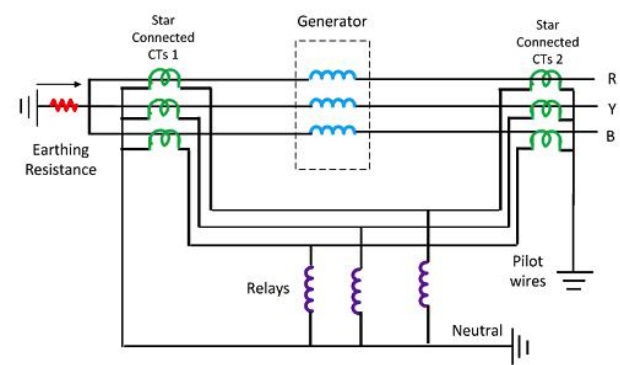

Fig. 4. Stator differential protection for generator.

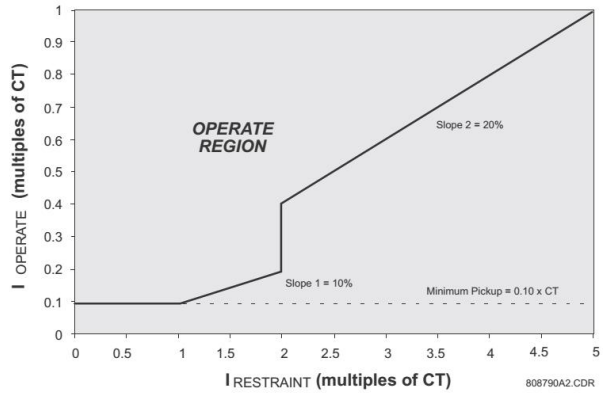

Fig. 5. Differential elements on new digital relay. [2]

The differential element for phase A will operate when

$$
I_{\text {operate }}>k \times I_{\text {restraint }}
$$

where the following hold

$$
\begin{aligned}
& I_{\text {operate }}=\bar{I}_{A}-\overline{I_{a}}=\text { operate current } \\
& I_{\text {restraint }}=\frac{\left|I_{A}\right|+\left|I_{a}\right|}{2}=\text { restraint current }
\end{aligned}
$$

$\mathrm{k}=$ characteristic slope of the differential element in percent

$$
k=\text { Slope1 if } I_{\text {restraint }}<2 \times C T ; k=\text { Slope } 2 \text { if } I_{\text {restraint }} \geq 2 \times C T
$$

$\mathrm{I}_{\mathrm{A}}=$ phase current measured at the output $\mathrm{CT}$

$\mathrm{I}_{\mathrm{a}}=$ phase current measured at the neutral end CT

\subsection{Current unbalance protection (46)}

There are numbers of system conditions that may cause a lack of symmetry of three-phase current in a generator. The most common causes are system asymmetries, unbalanced loads, unbalanced system faults, and open phases. These system conditions produce negativephase-sequence components of current which induces a double-frequency current in the surface of the rotor, the retaining rings, the slot wedges, and to a smaller degree, in the field winding. These rotor currents may cause high and possibly dangerous temperatures in a very short time.

A generator shall be capable of withstanding, without injury, the effects of a continuous current unbalance corresponding to a negative-sequence current $I_{2}$ of the following values on table 2, providing the rated $\mathrm{kVA}$ is not exceeded and the maximum current does not exceed $105 \%$ of rated current in any phase as shown as shown in figure 6 . 
Table 2. Constant Withstand Generator Limits. [3]

\begin{tabular}{|c|c|}
\hline Type of Generator & Permissible $\mathrm{I}_{2}$ (percent) \\
\hline Salient Pole & 10 \\
\hline With connected amortisseur windings & 5 \\
\hline With non-connected amortisseur windings & \\
\hline Cylindrical Rotor & 10 \\
\hline Indirectly Cooled & 8 \\
\hline Directly Cooled - to 960 MVA & 6 \\
\hline 961 to 1200 MVA & 5 \\
\hline 1201 to 1500 MVA & \\
\hline
\end{tabular}

The ability of a generator to accommodate unbalanced currents is specified in datasheet of generator in terms of negative sequence current $\mathrm{I}_{2}$. The negative sequence current is expressed as a percentage of rated stator current. The continuous $I_{2}$ capability of a generator and the short-time capability of a generator specified in terms $\mathrm{I}^{2} \mathrm{t}$. The existing setting is minimum pick-up at $4 \% \mathrm{FLA}$ and $\mathrm{K}=20$. The existing generator short-time capability is $I^{2} t=K=30$. Therefore, $K$ setting must be under 30 . The existing setting of $K=20$ and minimum pick-up of $4 \%$ is already sufficient protection of the generator. Therefore, the setting for the digital relay is also going to be set at $4 \%$, and $K=20$.

\subsection{Loss of excitation protection (40)}

Loss of field or loss of excitation results in loss of synchronism between rotor flux and stator flux. Under loss of excitation condition, the synchronous machine will operate as an induction machine at higher speed and draws more reactive power from the grid which results in the flow of slip frequency currents in the rotor body as well as severe torque oscillations in the rotor shaft. The rotor is not designed to sustain such currents or to withstand the high alternating torques which results in rotor overheating, coupling slippage and even rotor failure. This is where loss of excitation protection comes in handy.

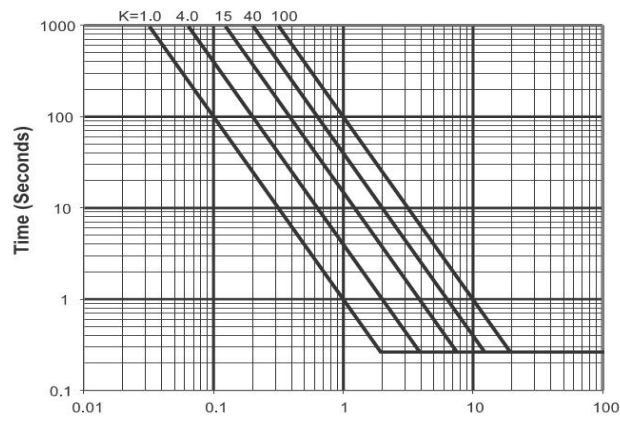

Fig. 6. Negative sequence current / rated current.

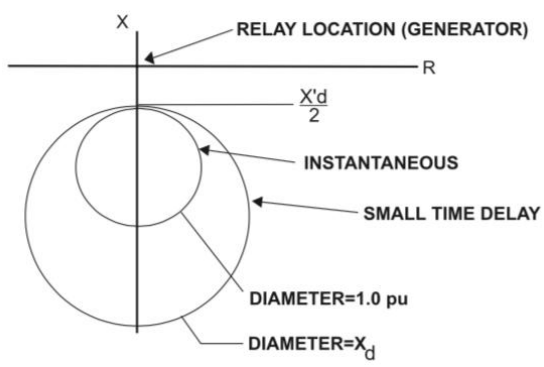

Fig. 7. Loss of excitation using impedance relay.

When impedance relaying is used to sense loss of excitation, the trip zone is typically marked by a mho circle centered about the $X$ axis, with an offset from the R axis by $X^{\prime} d / 2$ as shown in figure 7[4]. Two zones are used on occasions: a high speed zone and a time delayed zone. To protect the generator from loss of excitation occurrences, some parameters of generator as list on table 3 shall be considered: 
Table 3. Generator Parameter.

\begin{tabular}{|c|c|c|}
\hline No & Parameter & Value \\
\hline 1. & $\mathrm{X}^{\prime} \mathrm{d}$ & $0.23 \mathrm{pu}$ \\
\hline 2. & $\mathrm{Xd}$ & $1.65 \mathrm{pu}$ \\
\hline 3. & Base MVA & $15.625 \mathrm{MVA}$ \\
\hline 4. & Base kV & 13.8 \\
\hline 5. & CT Ratio & $1,000 / 5=200 / 1$ \\
\hline 6. & PT Ratio & $14,400 / 120=120 / 1$ \\
\hline
\end{tabular}

Then the setting can be calculated as follow:

$$
\begin{gathered}
Z_{\text {base(sec) }}=\frac{(k V \text { base })^{2}}{M N A \text { base }} \times \frac{C T \text { Ratio }}{\text { PT Ratio }} \\
Z_{\text {base(sec) }}=\frac{(13.8)^{2}}{15.625} \times \frac{200}{120}=20.31 \mathrm{ohm} \\
X^{\prime}{ }_{d}=Z_{\text {base(sec) }} \times X^{\prime}{ }_{d(\text { perunit) }}=20.31 \times 0.23=4.67 \mathrm{ohm}(\mathrm{sec}) \\
X_{d}=Z_{\text {base(sec) }} \times X_{d(\text { perunit) }}=20.31 \times 1.65=33.52 \mathrm{ohm}(\mathrm{sec})
\end{gathered}
$$

From this calculation, the relay setting can be calculated as follows:

Offset tap settings $=\frac{X_{d}{ }_{d}}{2}=\frac{4.67}{2}=2.33 \mathrm{ohm}$, use higher tap setting $2.5 \mathrm{ohm}$

Circle Diameter $=X_{d}=33.52 \mathrm{ohm}$, use lower tap setting $33.5 \mathrm{ohm}$

\subsection{Anti motoring or reverse power protection (32)}

Anti Motoring or Reverse Power Protection protects the generator and its prime mover (turbine) from drawing out power from the grid (motoring). Motoring of a generator will occur when turbine output is reduced to less than its no-load losses while the generator is still on-line. In this condition, the generator will operate as a synchronous motor and drive the turbine. The generator will not be harmed by synchronous motoring, but in contrast a steam turbine can be harmed by overheating during synchronous motoring if it lasted long enough. The motoring of the turbine output can be detected by reverse power protection.

The maximum motoring power of steam turbine is $3 \%$ of rated power (see table. 4 ), therefore the motoring load will be $3 \% \times 12.5 \mathrm{MW}=375 \mathrm{~kW}$. This number equal with secondary current of $0.078 \mathrm{~A}$. While for the minimum motoring power of steam turbine is $0.5 \%$ of rated power so the motoring load will be $0.5 \% \times 12.5 \mathrm{MW}=62.5 \mathrm{~kW}$ or equal with $0.013 \mathrm{~A}$ in secondary current. Therefore for setting will be within range $0.5 \%-3 \%$ or 0.5 - 3 per unit. Sufficient time delay should be provided to prevent undesired operation on transient power reversals such as those occurring during synchronizing or system disturbances. A setting of $2 \%$ of rated power is recommended with time delay of 5 seconds.

Table 4. Generator Maximum Motoring Power IEEE Std 242-2001 [1].

\begin{tabular}{|c|c|}
\hline Type of Prime Mover & Maximum Motoring Power of Unit Rating \\
\hline Gas Turbine & $50 \%$ \\
\hline 4 Cycle Diesel & $25 \%$ \\
\hline Steam Turbine & $0.5 \%-3 \%$ \\
\hline
\end{tabular}




\subsection{Overcurrent voltage restrain protection (51V)}

Generator overcurrent protection is provided by voltage restraint overcurrent protection relay $(51 \mathrm{~V})$. The voltage restraint overcurrent relay must be set higher than generator decrement curve and lower than generator damage curve at $100 \%$ voltage restraint.

In the voltage-restrained relay, the pick-up current varies as a function of voltage applied to the relay. In one type of relay with zero voltage restraint, the current pick-up is $25 \%$ of the pick-up setting with $100 \%$ voltage restraint as can be viewed in figure 8 . On units that have a short, short-circuit time constant, the $51 \mathrm{~V}$ voltage-restrained overcurrent relay should be used.

The pick-up current at full restraint voltage is set at 150\% of Full Load Amps. The pickup at no restraint must be lower than (Current FLA/Xd), based on IEEE recommendation. The existing protection setting is set at pick-up current of $1,000 \mathrm{~A}$ (5A secondary) and time dial 10.

FLA generator $=654 \mathrm{~A}$

Tap value $=I_{F L} \times \frac{1.5}{\text { CT Ratio }}=\frac{654 \times 1.5}{1000 \div 5}=4.905 A \approx 5 A \quad I_{\text {Fault }}=\frac{I_{F L}}{X_{d}}=\frac{654}{1.65}=396 A$.

At $0 \%$ voltage restraint, the relay will pick-up at: $I_{\text {pickup }}=5 \times 0.25 \times \frac{1000}{5}=250 \mathrm{~A}$

Since the fault current $\mathrm{I}_{\text {fault }}$ is higher than the pick-up current during $0 \%$ voltage restraint, the existing setting is adequate to protect generator during fault since the pick-up value is lower than the fault current (FLA/Xd).

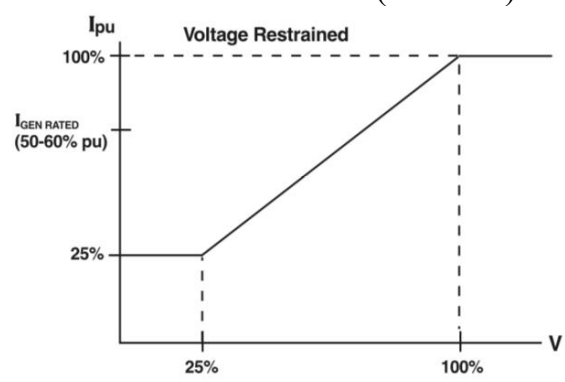

Fig. 8. Voltage-restrained time-overcurrent phase fault protection.

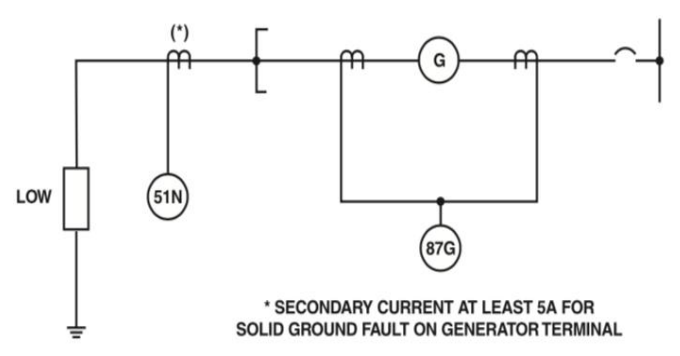

Fig. 9. Ground fault relaying for generator low impedance grounding.

\subsection{Stator ground fault protection (51GN)}

Normally the generator stator neutral operates at a potential close to ground. If a faulty phase winding is connected to ground, the normally low neutral voltage could rise as high as the line-to-neutral voltage depending on the fault location. Although a single ground fault will not necessarily cause immediate damage, the presence of one fault increases the probability of a second one. A second fault, even if detected by differential relay, may cause some serious damages.

If $87 \mathrm{G}$ relaying is provided, relay $51 \mathrm{GN}$ backs up the $87 \mathrm{G}$, as well as the external relays. If an $87 \mathrm{G}$ is not provided or is not sufficiently sensitive for ground faults, the $51 \mathrm{~N}$ will serve as the primary protection for the generator as shown in figure 9 . The advantage of the $87 \mathrm{G}$ is that there is no delay to coordinate with external protection; however, a delay is required for the $51 \mathrm{~N}[5]$.

The existing grounding system of generator is low impedance grounding with an $80 \Omega$ Neutral Ground Resistance (NGR), having with the capacity of 8000 V, 100 A for 10 seconds. There is a linear correlation between the current identified by ground fault relay and the ground fault position in the stator winding. The existing setting for stator ground 
fault is $20 \mathrm{~A}$ on primary side. It means that the relay will protect $80 \%$ of the generator winding.

\section{Cost and benefit analysis}

The investment cost on table 5 is acquired from equipment price (new numerical relay) and man power for installation, testing and commissioning.

Table 5. Total Investment Cost.

\begin{tabular}{|c|c|c|c|c|c|}
\hline No & Description & Price / Unit & Quantity & Total Cost & Remark \\
\hline 1. & Generator Protection & US\$ 9,200 & 14 & US\$ 128,800 & Refer to GE SR 489 \\
\hline 2. & Material Accessories & US\$ 500 & 14 & US\$ 7,000 & \\
\hline 3. & Installation Cost & US\$ 1,000 & 14 & US\$ 14,000 & \\
\hline 4. & $\begin{array}{c}\text { Service Engineer for Testing } \\
\text { and Commissioning }\end{array}$ & US\$ 2,000 & 14 & US\$28,000 & \\
\hline \multicolumn{4}{|c|}{ Total Investment Cost } & US\$ 177,800 & \\
\hline
\end{tabular}

While loss of production cost are derived from information on table 6 which shown the production loss due to nuisance trip or inability of generator protection to clear the fault in past time.

Table 6. Total Loss of Production Caused by Generator Protection Case.

\begin{tabular}{|c|c|c|c|c|}
\hline No & Date & Equipment & Outage Production & Outage LNG $\left(\mathrm{m}^{3}\right)$ \\
\hline 1. & 12 Oct 1988 & 31-PG-5 & 0.2 train days $(\mathrm{D})$ & 3,456 \\
\hline 2. & 26 Aug 1996 & 31-PG-4 & 0.65 train days $(\mathrm{A} \& \mathrm{~B})$ & 11,232 \\
\hline 3. & 22 Jul 1997 & 31-PG-2 & 1.39 train days $(\mathrm{A})$ & 23,018 \\
\hline 4. & 7 Mar 2001 & 31-PG-8 & 0.32 train days $(\mathrm{C})$ & 5,530 \\
\hline 5. & 24 Jul 2002 & 31-PG-8 & 0.18 train days $(\mathrm{C})$ & 3,067 \\
\hline 6. & 13 May 2014 & 31-PG-10 & - & - \\
\hline \multicolumn{4}{|c|}{ Actual LNG Loss Production } & US\$ 9,793,080 \\
\hline \multicolumn{4}{|c|}{ Total Average LNG Loss Production / Year (30 Years) } & US\$ 326,436 \\
\hline \multicolumn{5}{|c|}{$\begin{array}{l}\text { Remark: Assumption } \\
\text { - Liquid Density }=453 \mathrm{~kg} / \mathrm{m}^{3} \\
\text { - Higher Heating Value }=1,107 \mathrm{BTU} / \mathrm{SCF} \\
\text { - } 1 \mathrm{~m}^{3} \mathrm{LNG} \text { is equal with } 23.50 \mathrm{MMBTU} \\
\text { - LNG Price = US\$9/MMBTU }\end{array}$} \\
\hline
\end{tabular}

By definition, reliability function represents the probability that generator will have no nuisance trip at time " $\mathrm{t}$ " could be defined as

$$
R(t)=e^{-\lambda t}
$$

where $\mathrm{R}(\mathrm{t})=$ Reliability Function of generator, $\lambda=$ failure rate of generator protection.

Since 1988 or for 30 years, Badak LNG has been suffering 6 times of nuisance trip. It means the failure rate $\lambda=6 / 30$ years $=0.20$ / year.

Therefore Reliability per years of generator system in Badak LNG per year $R(t)=e^{-\lambda t}=e^{(-0.2)(1)}=0.819$ 
And then, the probability that the generator fail because of nuisance trip or inability to clear the fault.

$$
F(t)=1-R(t)
$$

$\mathrm{F}(\mathrm{t})=$ probability of failure $=1-0.819=0.181$

And the cost of consequences for not replace relay protection.

$$
E(t)=F(t) \times C
$$

$\mathrm{E}(\mathrm{t})=$ cost of consequences.

$\mathrm{C}=$ consequences, the amount of US\$ losses average in per year.

$\mathrm{E}(\mathrm{t})=0.181 \times \mathrm{US} \$ 326,436 /$ year $=$ US $\$ 59,085 /$ year.

With several assumptions basis data such as: project lifetime about five years and cost of capital Badak LNG about $10.18 \%$ so this replacement will give positive NPV (Net Present Value) started in fourth year (payback period in fourth year). From this result it can concluded that this project is justified from economical evaluation perspective.

\section{Conclusion}

Badak LNG had to start replacing the existing electromechanical relays with digital technology which has several advantages. New digital relay must have same setting with the previous to keep selectivity and proper function of machine. Replacement will give benefit to Badak LNG because it gives positive NPV (Net Present Value) from cost and benefit analysis point of view.

\section{Acknowledgments}

The author would like to thanks Mr. Rahmat Safruddin and Mr. Feri Sulistyo Nugroho for encouraging the author to write this paper and many thanks to all Maintenance and Operation Crew for making this project upgrading implemented.

\section{References}

1. IEEE Std 242-2001 Recommended Practice for Protection of Industrial and Commercial Power System

2. General Electric 2013489 Generator Management Relay Instruction Manual

3. IEEE Std C.37.102-2006 IEEE Guide for AC Generator Protection

4. Rockfeller G 1994 Generator Protection Application Guide (Basler Electric)

5. IEEE Std C.37.101-1993 IEEE Guide for Generator Ground Protection 